\title{
Change of the Decorative Properties of Zinc-Plated Zinc Die Castings over Time
}

\author{
Reveko, Valeriia; Lampert, Felix; Winther, Grethe; Møller, Per
}

Published in:

International Journal of Metalcasting

Link to article, DOI:

10.1007/s40962-018-0237-0

Publication date:

2019

Document Version

Peer reviewed version

Link back to DTU Orbit

Citation (APA):

Reveko, V., Lampert, F., Winther, G., \& Møller, P. (2019). Change of the Decorative Properties of Zinc-Plated Zinc Die Castings over Time. International Journal of Metalcasting, 13(1), 130-136.

https://doi.org/10.1007/s40962-018-0237-0

\section{General rights}

Copyright and moral rights for the publications made accessible in the public portal are retained by the authors and/or other copyright owners and it is a condition of accessing publications that users recognise and abide by the legal requirements associated with these rights.

- Users may download and print one copy of any publication from the public portal for the purpose of private study or research.

- You may not further distribute the material or use it for any profit-making activity or commercial gain

- You may freely distribute the URL identifying the publication in the public portal

If you believe that this document breaches copyright please contact us providing details, and we will remove access to the work immediately and investigate your claim. 


\title{
CHANGE OF THE DECORATIVE PROPERTIES OF ZINC-PLATED ZINC DIE CASTINGS OVER TIME
}

\author{
Valeriia Reveko \\ Collini GmbH, Hohenems, Austria \\ Materials and Surface Engineering, Department of Mechanical Engineering, Technical University of Denmark, \\ Kongens Lyngby, Denmark \\ Felix Lampert, Grethe Winther, and Per Møller \\ Materials and Surface Engineering, Department of Mechanical Engineering, Technical University of Denmark, \\ Kongens Lyngby, Denmark
}

\begin{abstract}
Zinc alloy die casting is often chosen for the manufacturing of various consumer goods, since this process allows manufacturing of parts with a consistent quality and a high cost efficiency. With regard to recycling, using zinc electrodeposition as a surface treatment for zinc die cast offers clear advantages. However, it is often noticed that bright zincplated coatings on zinc die cast components change color over time, developing distinct blue spots on the sur-face. In the present study, zinc-plated zinc die cast com-ponents were aged and characterized via Energy-Dispersive X-ray Spectroscopy, $X$-ray diffraction, and gloss and color analyses to make a conclusion on the mechanism of tarnishing. It was found that over time aluminum from the substrate diffuses through the coating, with the different diffusion rates for the coatings that were deposited from the different electrolyte types. Thus, alka- line zinc showed higher rates of aluminum diffusion com-pared to acid zinc. It was speculated that aluminum diffusion through the coating followed by oxidation under the influence of ambient moisture and contaminants trig-gers the observed blue discoloration.
\end{abstract}

Keywords: electroplating, zinc die cast, zinc plating, color change, decorative surface finishing 


\section{Introduction}

Metal die casting is a popular choice for the manufacturing of various consumer goods. Industrial producers are increasingly attracted by this economical and efficient process capable of providing near-net shape components which satisfy the required geometrical tolerances and do not require additional machining. ${ }^{1}$ Zinc as a working material offers a broad range of attractive properties such as hardness, ductility, dimensional stability, self-lubricat- ing behavior, and high heat conductivity. ${ }^{2,3}$ However, since unalloyed zinc results in a brittle material with a low strength, additional alloying elements are required to obtain the desirable material characteristics. Among all zinc die casting alloys, the "Zamak" family, consisting of pure zinc alloyed with small amounts of aluminum, mag- nesium, and copper, ${ }^{4}$ is the most common choice owing to its good castability and dimensional stability. Furthermore, its moderate solidification temperature (less than $400{ }^{\circ} \mathrm{C}$ ) ensures high production rates and yields, in an energy efficient process, with a long working life for the tools. ${ }^{5}$

The addition of aluminum improves the fluidity of these alloys and lowers their melting point. ${ }^{6}$ Small amounts of copper (up till 3.3\%) increase the tensile strength and hardness, ${ }^{7}$ and magnesium confers higher resistance to intergranular corrosion that can occur in the presence of impurities. All these agents are essential for achieving a highquality die casting material; however, they may also cause negative side effects. The presence of copper inclu- sions at the surface can create galvanic coupling with zinc and aluminum, and since these two are characterized by a more negative potential than copper, their corrosion can be easily promoted. ${ }^{8}$ Untreated zinc is prone to corrosion in acid as well as in strong alkaline environments and in industrial atmospheres. Since corrosion is often promoted by surface impurities, the surface treatment of zinc die cast components by electroplating is a common practice. Hereby, the most common coating systems applied for decorative and pro- tective purposes are nickel with a top coat or nickel and hexavalent chromium over a cyanide copper strike, as is proposed by the ASTM B252 standard; ${ }^{9}$ however, for modern industries that are aiming for environmentally friendly and sustainable solutions, the conventional haz- ardous and potentially allergenic surface treatments are not satisfying. ${ }^{10}$ Furthermore, the use of hexavalent chrome solutions is banned according to Annex XVII of REACH ${ }^{11}$ in the European Union, while the substitution of trivalent chromium electrolytes that have the same performance as the traditional hexavalent electrolytes are still under development.

Although zinc is one of the most common elements in the earth's crust, it is an example of an 'extremely scarce resource'. ${ }^{12}$ It was anticipated, given the contemporary trend in consumption, that most metals (including zinc) will be exhausted before the year 2100. Therefore, efforts to recycle zinc and consume the material in a more sustainable manner have become increasingly important. Since the production of recycled zinc requires less than $10 \%$ energy consumption compared to primary zinc, ${ }^{13}$ there is a high industrial need for recyclable zinc components. However, complex systems of $\mathrm{Cr}$ and $\mathrm{Ni}$ coatings on zinc substrates are difficult to recycle, giving an incentive to change to more recyclable coating solutions.

Along these lines, zinc plating on zinc die cast substrates offers explicit advantages with respect to the incumbent nickel/chromium systems and grants environmentally friendly surface treatments with excellent recyclability. From the decorative and protective point of view, bright passivated zinc is a popular type of surface finishing ${ }^{14}$ however, the process is challenging on zinc die cast com- ponents, because the components might develop a blue color at the surface after several months of storage, and thus fail decorative specifications. ${ }^{15}$ Although such dis- coloration of the coatings is a major challenge for the application of zinc plating on die cast components, the reason for it has not been described in the literature before. Hence, this work focuses on a detailed investigation of plated zinc die cast tarnishing. Acid and alkaline zinc is deposited on zinc die cast components and an accelerated aging experiment is performed. Both the aged and initial conditions are investigated by Scanning Electron Micro- scopy (SEM), Energy-Dispersive X-ray Spectroscopy (EDS), X-ray diffraction (XRD), as well as gloss and color analyses. A technically viable solution to prevent the tarnishing is then discussed. 


\section{Materials and Methods}

Zinc die cast samples made of Zamak 5 (Al 3.7-4.3, Cu 0.7-1.2, Mg 0.02-0.06 according to ASTM B86 ${ }^{4}$ ) were cathodically degreased and activated in 1:10 dry acid (sodium hydrogen difluoride) diluted with water. Afterward, the samples were electroplated either with $\sim 10 \mu \mathrm{m}$ of acid zinc (Bright Zinc SLOTANIT OT 1, Schlötter Galvanotechnik) or $\sim 10 \mathbf{\mu m}$ of alkaline zinc (Bright Zinc SLOTOCYN 10, Schlö tter Galvanotechnik) or with $\sim 5 \mathrm{\mu m}$ of acid copper (Cupracid 210, Atotech) followed by $\sim 10 \mu \mathrm{mm}$ of alkaline zinc (Bright Zinc SLOTOCYN 10, Schlötter Galvanotechnik). After plating, the samples were brightened with 1 vol\% solution of nitric acid (SigmaAldrich) and then passivated with a trivalent chromium passivation solution (SLOTOPAS Z 20 Blue, Schlötter Galvanotechnik).

For the accelerated aging, the samples were kept in an electric furnace at a temperature of $70{ }^{\circ} \mathrm{C}$ for 12 weeks. To monitor possible tarnishing and color change, gloss and color measurements were taken in weekly intervals using an Elcometer 408 glossmeter with 85 measurement angle and Elcometer 6085 spectrophotometer, respectively. Gloss measurements were exhibited in gloss units (GU). For presenting color measurements, a CIELAB (Commission Internationale de l'Éclairage) color scale was used, where $L^{*}$ value expressed lightness-darkness of the sample, a* axis described the green-red component, and $b^{*}$ represented the blue-yellow component of the color space. An average value out of measuring three samples of each kind was taken, from fixed measurement spots: two for gloss measurements and four for color measurements. The gloss measurements were discontinued after 8 weeks, since it was not possible to obtain consistent values over the sur- face, presumably due to uneven tarnishing of the surface and large measuring window of the Elcometer 408.

After 12 weeks of accelerated aging, coating cross sections of aged samples and non-aged reference samples were prepared by epoxy cold molding, mechanically polished down to a $1 \mathrm{Im}$ diamond paste finish and etched with 10 mass $\%$ sodium hydroxide solution for $5 \mathrm{~s}$. Subsequently, the samples were investigated by Scanning Electron Microscopy (SEM) and chemical analysis by Energy-Dis- persive X-ray Spectroscopy (EDS) on a JEOL JSM-5900 instrument fitted with a LaB 6 filament electron source and an Oxford Instruments EDS detector. The microscope was operated at 20-kV accelerating voltage.

The crystallographic texture of the electrodeposited coat- ings was measured using a Bruker D8 Discovery Diffractometer. Partial (0002), (10-10), and (10-12) pole figures were measured up to an angle of $65^{\circ}$. Based on the three measured partial pole figures, the full pole figures were calculated.

\section{Results}

Figure 1 shows samples directly after plating and passi- vation (a) and after accelerated aging (b). The dark blue color of the alkaline zinc-plated sample was not noticeable right after withdrawal from the oven, however, appeared after 1 day of storage in air without direct access to sunlight.

Gloss measurements showed different levels of tarnishing for the different coating systems over the period of monitoring (Figure 2). The alkaline zinc and alkaline zinc coatings with intermediate copper layers show a compa- rable level of gloss after the samples were plated. In con- trast, the acid zinc-plated samples appeared duller, and exhibited more than 20 gloss units less compared to both types of alkaline zinc-plated samples. During the acceler- ated aging, the alkaline zinc-plated samples showed no significant loss in glossiness, while the acid zinc-plated samples showed a minor decrease in glossiness and alka- line zinc-plated samples with intermediate copper layers had a gloss loss of 19 units.

Color measurements showed a similar tendency (Figure 3). The lightness of the samples follows the same trend, except that the change for the acid zinc-plated samples and alka- line zinc samples with the copper layer has a more pronounced decrease. On the "red-green" channel of CIELAB scale (a values) the relation is varied, while on the "yellowblue" channel (b values) there is a clear tending towards more blue values. 
The results of SEM imaging of the cross sections were aligned with EDS line profiles, as shown in Figure 4. The first column shows the images of the samples without heat treatment (a, c, and e), while the second column shows the samples after accelerated aging. Some differences between the layer thicknesses of the intermediate copper layer and acid zinc layer stated in the experimental section and the ones seen from the images originates from the partial disturbance of the plating process and is not expected to affect the general result. As it can be seen in Figure $4 a$, the reference alkaline zinc-plated sample with copper intermedi- ate layer shows clear division between the layers, and no foreign elements were detected in the zinc coating. The same coating system after aging (Figure 4b) shows sig- nificant copper diffusion into the upper zinc layer (from almost $30 \mathrm{wt} \%$ in bulk to $2.5 \mathrm{wt} \%$ at the surface). The reference alkaline zinc-plated sample shows some traces of aluminum in the zinc coating layer (Figure 4c). After aging, the amount of aluminum increases and reaches

* $1 \mathrm{wt} \%$ in the coating and on the surface, as it is indi- cated in Figure $4 \mathrm{~d}$. In contrast to the alkaline zinc sample, the acid zinc-plated sample shows no presence of alu- minum in the coating layer of the reference sample (Figure 4e); however, after aging there is an indication of aluminum in the coating (Figure $4 \mathrm{f}$ ). The surface content of aluminum was measured at * $0.5 \mathrm{wt} \%$.

Texture data in the form of measured and calculated pole figures are shown in Figure 5 . The reference alkaline zincplated sample with intermediate copper layer (Figure 5a) has a dominant texture fiber with the pyramidal (10-10) plane parallel to the substrate, as indicated by the high intensity in the center of the (10-10) pole figure, which is consistent with the high intensity along the circumference of the (0002) pole figure. A minor fiber with the basal (0002) plane parallel to the substrate is also present. Aging (Figure $5 b$ ) intensifies original fiber texture.

By contrast, the pole figures for the reference sample of zinc die cast directly plated with alkaline zinc (Figure $5 c$ ) demonstrate dominance of the texture fiber with the basal plane parallel to substrate. There is a minor fiber for which the (10-10) pyramidal plane is tilted somewhat out of the plane of the substrate as evidenced by the ring close to the center of the (10-10) pole figure. Aging has no significant influence.

The acid zinc-plated zinc die cast for the reference sample has two fibers with the (0002) basal plane and the (10-10) pyramidal parallel to the substrate. The (0002) fiber is stronger but the (10-10) fiber also has significant intensity. Aging has no significant influence.

\section{Discussion}

The accelerated aging of the zinc-plated die cast compo- nents demonstrated that structural changes in the coating may occur over time. Moreover, the coatings that were deposited from the different electrolytes (i.e., acid and alkaline) showed different behaviors. The alkaline zinc coating plated directly on the zinc die cast substrate showed the most visible degradation in optical appearance. Notably, no significant changes were noticed while sam- ples were kept in the oven, but a distinctive blue color appeared after storing samples for 1 day in air. A similar degradation was previously reported by Kushner, ${ }^{15}$ who noted that zinc-plated zinc die cast components are getting a blue color after several months of storage. Based on EDS analysis, we found that aluminum from the substrate is mobile in the coating and may reach the coating surface via a diffusion process. Thus, we propose that aluminum dif- fusion through the coating followed by oxidation under the influence of ambient moisture and contaminants triggers the observed blue discoloration.

Furthermore, we have shown that the addition of an intermediate copper barrier layer prevented the diffusion of aluminum. Our observations are in agreement with the results from Kushner, ${ }^{15}$ who described that unwanted color change of alkaline zinc-plated die cast components may be prevented by the application of a copper barrier layer. Even after accelerated aging, the surface remained shiny and the blue discoloration did not appear. However, as the EDS analysis showed (Figure 4b), a pronounced copper diffu- sion is evident. Binary copper-zinc alloys are well known to form a variety of intermetallic phase ${ }^{16}$ and the observed step-like change in copper-zinc ratio, which can be seen from Figure $4 \mathrm{~b}$, likely originates from the formation of different copper-zinc phases in the coating. These inter- metallic 
phases are expected to have a different electro- chemical potential with respect to zinc, leading to galvanic coupling with the surface. Thus, we presume that an intermediate copper layer may intensify localized corrosion of the coating system and cannot be recommended as industrially viable solution for protective decorative coat-ings. The exact effect of an intermediate copper barrier layer on the electrochemical characteristics of the coating system needs to be evaluated in further research.

Acid zinc did not show blue discoloration after aging. The EDS analysis (Figure 4f) indicated a lower level of aluminum diffusion compared to alkaline zinc. This can be explained by the differences in the grain structure of these two coatings. As it was reported by Schlesinger et al., ${ }^{17}$ deposition from alkaline zinc electrolytes triggers the for- mation of columnar structures, whereas coatings from acid electrolytes have laminar character. Consequently, the columnar structure of the coatings from alkaline electrolytes may enable accelerated diffusion of aluminum to the surface via low diffusivity path ${ }^{18}$ along the columnar grain boundaries, and thus account for the high suscepti- bility of the coatings to discoloration. Conversely, the laminar structure of coatings from acid environments does not accelerate the transport of substrate elements to the surface, leading to a significant retardation in tarnishing kinetics. Although preferred growth directions in terms of grain shapes does not necessarily correlate with preferred crystallographic directions, the texture difference between the alkaline and acid platings indicate different growth patterns. The more diffuse (10-10) fiber in the acid plating may suggest a longer effective diffusion path for aluminum atoms.

However, the gloss measurements indicated that the gloss of acid zinc degrades faster compared to alkaline zinc (Figure $3 b$ ). Biddulph ${ }^{19}$ showed that zinc coatings deposited from acid baths are less resistive to corrosion when compared to coatings deposited from alkaline baths.

Consequently, we propose that the more advanced loss in glossiness originates from a lower corrosion resistance, and thus accelerated tarnishing of the surface.

Overall, the analysis has shown that none of the investi- gated systems fully satisfies the industrial requirements ofa highly protective character together with a high resistance towards discoloration and a long-lasting glossiness. How- ever, we have demonstrated that the application of an intermediate barrier layer can efficiently suppress the dif- fusion of aluminum through the decorative zinc coating, and thus suppress the initiation of blue discoloration. As a viable solution, we propose the application of a double- layered zinc coating with an inner layer deposited from acid electrolyte, which delays the transport of aluminum to the surface, combined with an outer layer deposited from alkaline electrolyte, which offers a high resistance towards tarnishing and guarantees long-lasting gloss. The performance of double-layered zinc coatings to overcome the present technological challenges needs to be evaluated in further research.

\section{Conclusions}

In summary, we have investigated the mechanism of blue discoloration of zinc die cast components finished with a decorative electroplated zinc coating. Blue discoloration has been found to originate from the diffusion of aluminum from the die cast alloy to the surface, followed by oxidation of the aluminum-rich surface. The application of an inter-mediate metallic layer between the die cast and the deco- rative finish can efficiently suppress the transport of aluminum through the coating. Copper was found inap- propriate as an intermediate layer, since diffusion of copper into the decorative finish was observed and galvanic cou- pling between copper and zinc is expected to deteriorate the corrosion properties of the system. Zinc coatings plated from an acid electrolyte showed a higher resistance towards aluminum diffusion compared to coatings plated from an alkaline electrolyte, since alkaline zinc exhibited a columnar grain structure which enabled accelerated diffusion via high diffusivity paths. A double-layered zinc coating with an inner layer of acid zinc and an outer layer of alkaline zinc was proposed as a viable solution to overcome issues with blue discoloration while maintaining an attractive decorative appearance. 


\section{Acknowledgements}

We thank Linimatic $\mathrm{A} / \mathrm{S}$ for providing zinc die cast components for the testing, Vittorio Albertazzi for working on the color and gloss measurements, Flem- ming Bjerg Grumsen for assisting during the X-ray diffraction analysis and Niels Ulrik Gjerløff for the proof reading. We also gratefully acknowledge Martin Peter and Martin Netzer for industrial perspective contribution.

\section{Funding}

This work was done in the frame of Industrial PhD project at MTU MEK DTU supported by Collini GmbH (Project Number 76665, Task T-4).

\section{REFERENCES}

1. F. Porter, Zinc Handbook: Properties, Processing, and Use in Design (Dekker, New York, 1991)

2. K. Miyoshi, Solid Lubricants and Coatings for Extreme Environments: State-of-the-Art Survey (National Aeronautics and Space Administration, Springfield, 2007)

3. J.V. Wesemael, A performance evaluation of modern surface finishes for zinc die castings -a summary. Die Cast. Eng. 51(2), 36-38 (2007)

4. Active Standard ASTM B86 Standard Specification for Zinc and Zinc-Aluminum (ZA) Alloy Foundry and Die Castings. West Conshohocken, PA, ASTM Interna- tional (2013)

5. M. Gelfi, E. Bontempi, A. Pola, R. Roberti, D. Rollez, L.E. Depero, Microstructural and mechanical proper- ties of zinc die casting alloys. Adv. Eng. Mater. 6(10), 818-822 (2004)

6. D.K. Gross, Zinc die casting: the importance of alloy chemistry. Die Cast. Eng. 47(2), 30-31 (2003)

7. M.T.T. Savaskan, Relationships between cooling rate, copper content and mechanical properties of mono- tectoid based Zn-Al-Cu alloys. Mater. Charact. 51, 259-270 (2003)

8. I. Muto, H. Yoshida, H. Ogawa et al., Effect of alloying elements on atmospheric corrosion behavior of zinc diecasting alloys. J. Jpn. Inst. Met. 72(5), 337-346 (2008)

9. Active Standard ASTM B252, Standard Guide for Preparation of Zinc Alloy Die Castings for Electro- plating and Conversion Coatings, West Con- shohocken, PA, ASTM international (2014)

10. Rourke, D, "Corrosion performance of "green" fin- ishes on zinc die castings" SAE 2011 World Congress and Exhibition, Detroit, March 2011

11. ANNEX XVII to REACH - Entry 47 for chromium VI compounds, European chemical agency

12. J.B. Legarth, Sustainable metal resource manage- ment-the need for industrial development: efficiency improvement demands on metal resource management to enable a (sustainable) supply until 2050. J. Clean. Prod. 4(2), 97-104 (1996)

13. R.B.H. Tan, H.H. Khoo, LCA case studies zinc casting and recycling. Int J LCA 10, 211-218 (2004)

14. M. Wyrostek, P. Wynn, Driving away from hex chrome coatings. Met. Finish. 104(4), 22-29 (2006)

15. A.S. Kushner, How can we prevent zinc die cast parts from changing color after zinc plating? Product Fin- ishing online (2014)

16. A. Cohen, ASM International (Properties of Cast Copper Alloys. Copper Development Association Inc., Cleveland, 1990)

17. M. Schlesinger, M. Paunovic, Modern Electroplating, 5th edn. (Wiley, Hoboken, 2010)

18. D.A. Porter, K.E. Easterling, High-diffusivity paths, Phase Transformations in Metals and Alloys (Chap- man \& Hall, London, 1992)

19. C. Biddulph, Zinc Electroplating. Products Finishing,

20. Fundamentals Post (2011) 
Figures

(a)

Zinc die cast / copper /

alkaline zinc

Zinc die cast / alkaline zinc

Zinc die cast /acidic zinc
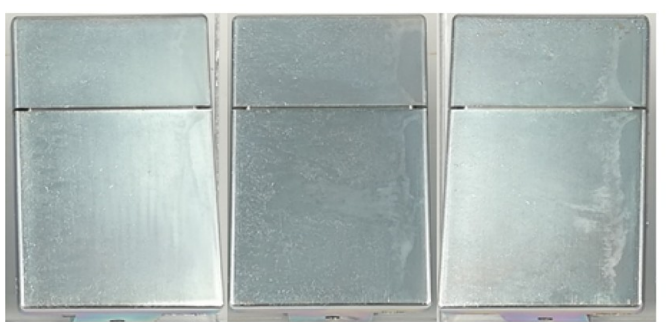

(b)

Zinc die cast / copper / alkaline zinc

Zinc die cast /

Zinc die cast /acidic zinc
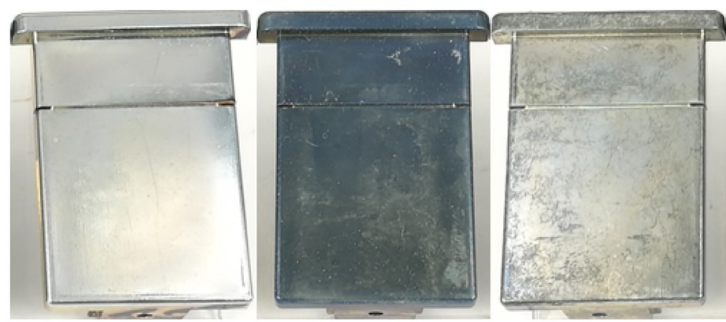

Figure 1. Photos of zinc-plated zinc die cast components: (a) samples after plating and passivation, and (b) samples after accelerated aging followed by 2 days of storage under ambient conditions.

- Culalkaline $\mathrm{Zn} \cdots$ alkaline $\mathrm{Zn}-\mathbf{-}$ acidic $\mathrm{Zn}$

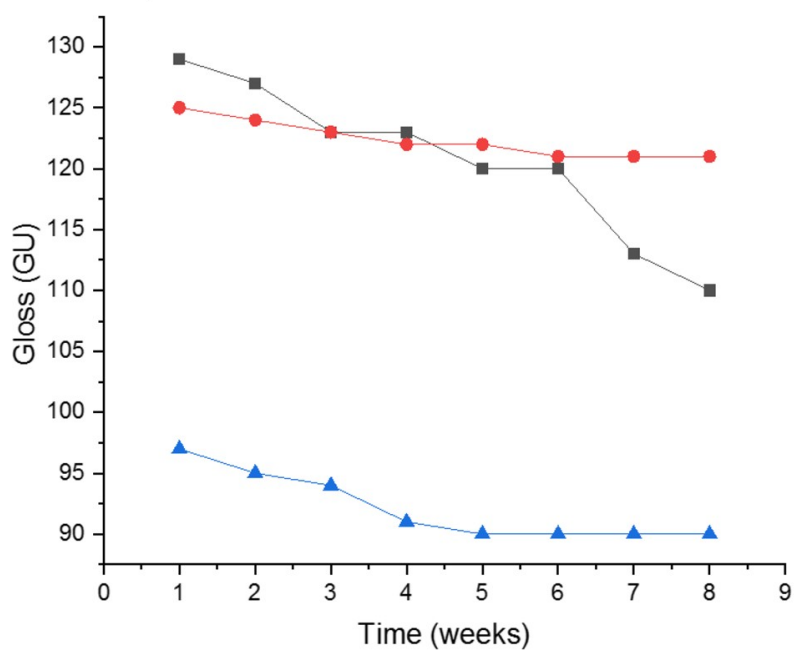

Figure 2. Values in gloss units (GU) for the gloss change of the tested samples during accelerated aging.
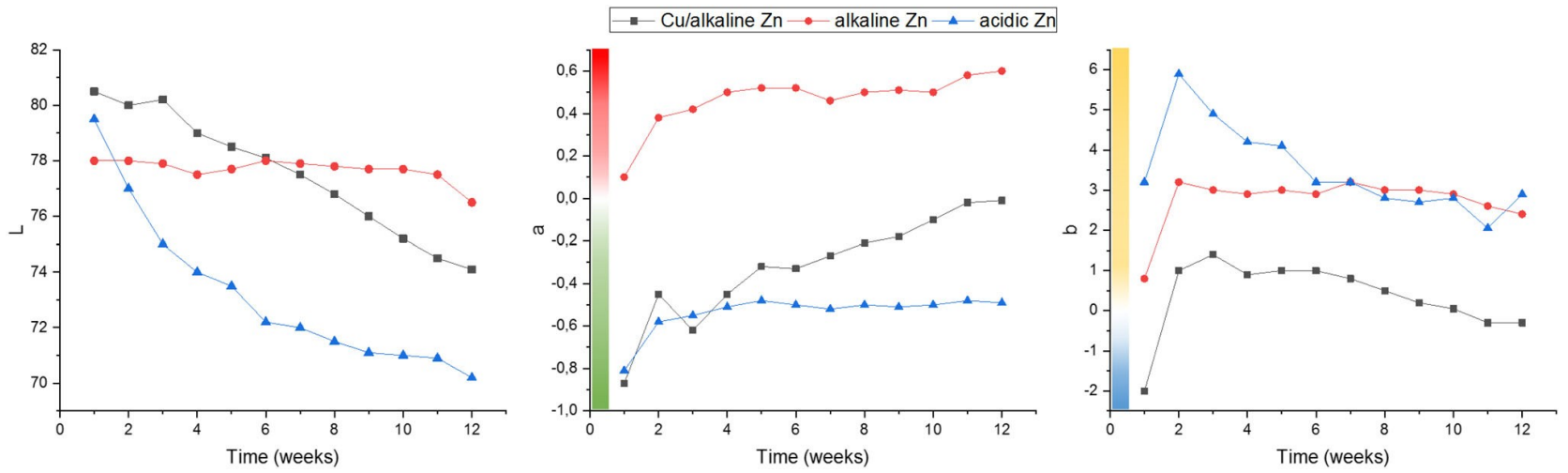

Figure 3. Values in CIELAB scale for the color change of the tested samples during accelerated aging. L shows the lightness value; (a) and (b) The color opponents green-red and blue-yellow. 

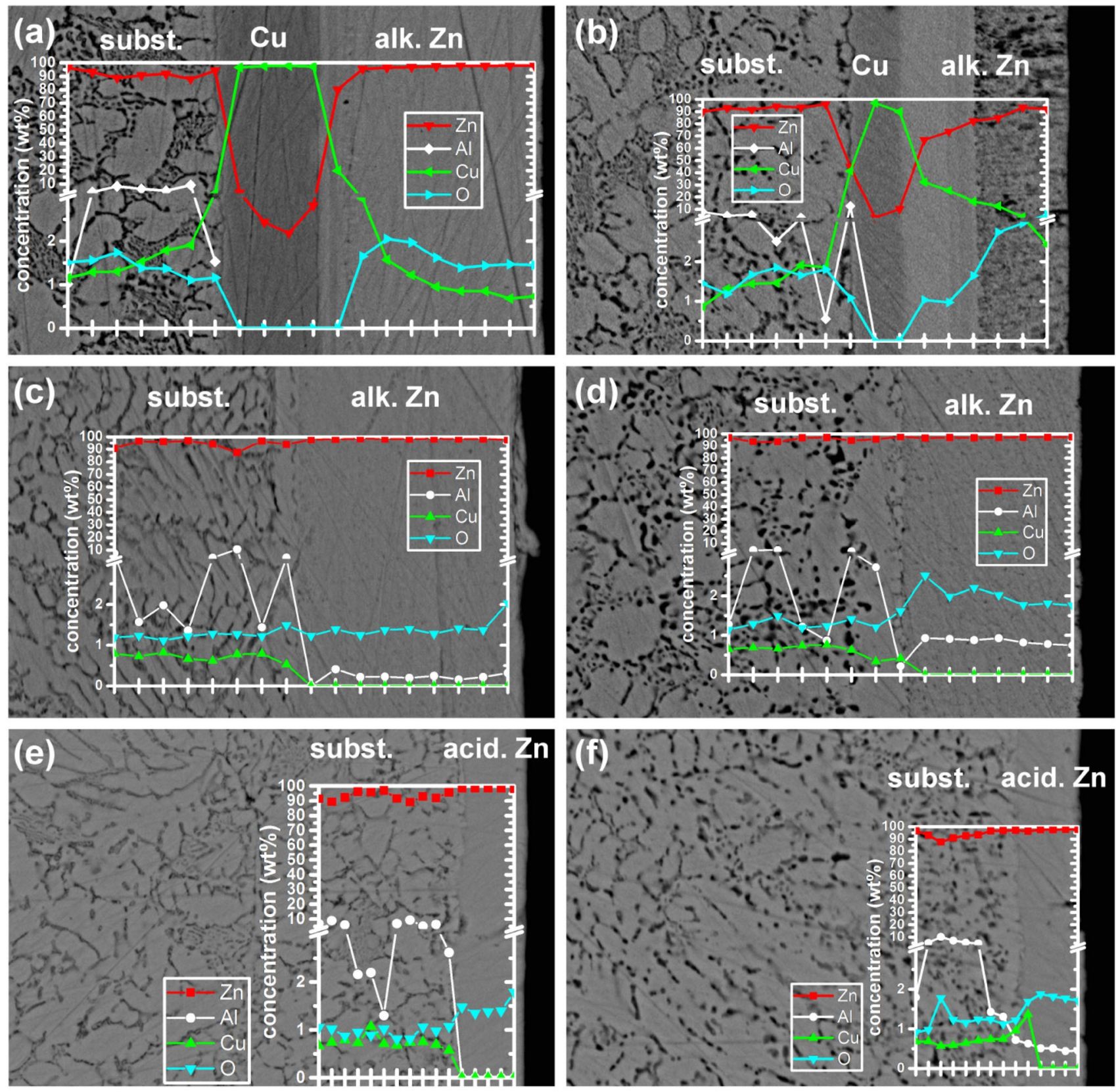

$30 \mu \mathrm{m}$

Figure 4. Backscatter SEM micrographs of zinc-coated samples with overlaying EDS line profile: (a) alkaline zinc coating with intermediate copper layer, (b) alkaline zinc coating with intermediate copper layer (aged), (c) alkaline zinc coating, (d) alkaline zinc coating (aged), (e) acid zinc coating, and (f) acid zinc coating (aged). 


\section{Reference samples}

Zinc die cast / copper / alkaline zinc

Zinc die cast / alkaline zinc

(c) 0002

$10-10$

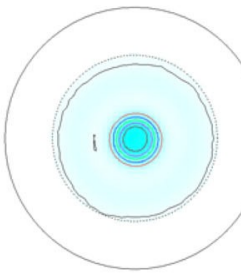

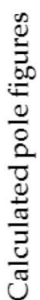

\section{Acceleratedly aged samples}

Zinc die cast / copper / alkaline zinc

(b) 0002

$10-10$
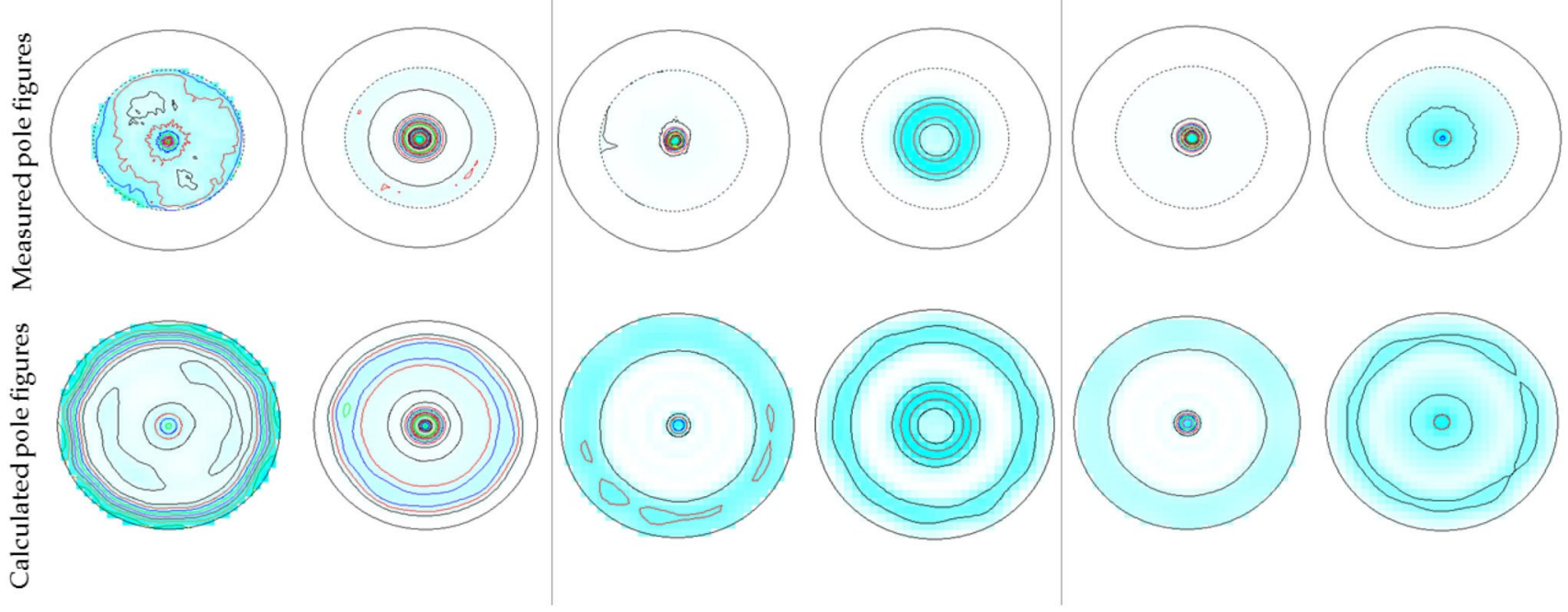

Zinc die cast / alkaline zinc

(d) 0002

$10-10$

(f) 0002

Zinc die cast / acidic zinc
Zinc die cast / acidic zinc

(e) 0002

$10-10$

Figure 5. Measured and calculated pole figures: (a) alkaline zinc coating with intermediate copper layer, (b) alkaline zinc coating with intermediate copper layer (aged), (c) alkaline zinc coating, (d) alkaline zinc coating (aged), (e) acid zinc coating, and (f) acid zinc coating (aged). 